\title{
The qualitative learning experience of healthcare workers completing a hybrid workplace violence educational program
}

\author{
Gordon Lee Gillespie ${ }^{1}$, Sharon Lee Farra ${ }^{2}$, Donna M. Gates ${ }^{1}$, Patricia Kunz Howard ${ }^{3}$, Kristy L. \\ Atkinson $^{4}$
}

1. College of Nursing, University of Cincinnati, Cincinnati, USA. 2. Department of Nursing, Miami University, Middletown, USA. 3. Emergency Services, University of Kentucky Chandler Medical Center, Lexington, USA. 4. Emergency Department, Cincinnati Children's Hospital Medical Center, Cincinnati, USA

Correspondence: Gordon Lee Gillespie. Address: College of Nursing, University of Cincinnati, P.O. Box 210038, Cincinnati, OH 45221-0038, USA. Email: Email: gordon.gillespie@uc.edu.

Received: January 20, 2013

DOI : $10.5430 /$ jnep.v3n11p54
Accepted: February 21, $2013 \quad$ Online Published: April 15, 2013

URL: http://dx.doi.org/10.5430/jnep.v3n11p54

\section{Abstract}

Background: Hybrid educational methodologies which include online and classroom-based learning experiences increase learning. However, the course delivery preferences of learners need to be evaluated so the design and delivery of future programs will maximize learning outcomes. The aim of this study was to describe how the delivery of a hybrid program contributes to learning outcomes.

Methods: A qualitative descriptive design was used. Participants were recruited from two large emergency departments that completed a hybrid workplace violence educational program. Four focus group sessions were held with a convenience sample of 17 participants to discuss their learning experience with the hybrid educational program. Sessions were audiotaped and transcribed verbatim. Data were analyzed using a constant comparative analysis method.

Results: Three themes emerged from the data. The first theme was "Implementation of the Intervention" and represented the opportunity for learning, the environment of learning, and the need for uniform training. The second theme was "Experience of the Intervention" and represented the conditions of learning, interdisciplinary learning, facilitated engagement, and realism of the learning content. The third theme was "Translation of the Intervention" which represented the transferability and retention of the program content.

Conclusion: An active learning classroom-based component was perceived to yield greater knowledge attainment and retention than online learning for the participants in this study. Consideration of the learning styles and needs of learners should be taken into consideration when developing content for the online delivery or hybrid approach for educational programs.

\section{Key words}

Web-based, Online, Classroom, Traditional, Distance, Hybrid approach, Blended education, Tabletop exercise, Focus groups 


\section{I ntroduction}

Nursing education is offered in varying formats including traditional delivery (face-to-face classroom), distance delivery (online learning), and hybrid approaches (traditional delivery and distance delivery) ${ }^{[1]}$. Traditional delivery can be more costly and may be difficult to schedule a mutually convenient time for learners and teachers(s). Benefits of traditional delivery include (1) the simultaneous delivery and discussion of content between faculty and students ${ }^{[1]}$, (2) opportunity for leaners to ask questions with all students hearing the same response, and (3) ability of teachers to make inferences for student understanding based on nonverbal communication (e.g., students frowning, students rubbing their heads). Online learning has the potential to be less expensive and offer better scheduling access, but may not yield the same desired learning outcomes. Hybrid approaches include both traditional delivery and some form of distance delivery and can be a superior method for achieving both learning and retention of new content ${ }^{[2]}$. To add to this body of knowledge, it is important and thus the purpose of this article to evaluate the experiences of adult learners to determine their preferences for learning approaches. In the following paragraphs, we will introduce hybrid methodologies as a classroom design to facilitate active learning and build a case for the need to implement a hybrid (online learning coupled with a tabletop exercise) methodology designed to provide education on an issue of clinical importance to emergency department (ED) workers.

There is strong evidence indicating those hybrid methodologies which include online and traditional approaches increase learning by offering a more comprehensive approach than either method alone ${ }^{[2,3]}$. Online modules help learners focus on key topics and rehearse information. Learners progress at their own pace with information presented in smaller units to decrease the cognitive load ${ }^{[4]}$. The addition of an active learning classroom-based experience increases learners' participation in the learning process. Researchers have established that active learning strategies lead to improved learning outcomes ${ }^{[5]}$. Active learning techniques are educational interventions where learners participate in activities focused around learning content ${ }^{[6]}$. Examples of active learning are classroom discussion, analyzing and reacting to videos, and role-playing ${ }^{[7]}$.

An active learning strategy suitable to a hybrid methodology is the tabletop exercise. A tabletop exercise is a dynamic active educational strategy where learners gather around a table with the aim of discussing simulated emergency situations ${ }^{[8]}$. Tabletop exercises have demonstrated effectiveness in improving learning using simulated scenarios, interactive activities, and discussions ${ }^{[9]}$. During tabletop exercises, learners are engaged within an interprofessional environment to discuss and problem-solve situations in a slower-paced simulated setting ${ }^{[10]}$. Tabletop exercises are active learning strategies needing further evaluation to determine effectiveness in achieving learning outcomes ${ }^{[9]}$. In addition to achieving learning outcomes, educational programs should also have immediate relevance to learners.

Actively learning is not restricted to academic settings. Active learning strategies are needed to address many clinical issues in healthcare. A significant problem for ED workers is the alarming increase in the rate of physical violence and threats against them by patients and visitors as well as the devastating consequences of violence ${ }^{[11-16]}$. There is an urgent need to reduce these attacks ${ }^{[17]}$. An effective and relevant educational intervention is a much needed strategy to promote the safety of ED workers and decrease the rate of workplace violence against them ${ }^{[18,19]}$. There is a dearth of educational interventions with published evaluation data to depict if the programs are achieving their aims from the learners perspective. In addition, the few published workplace violence educational interventions existing have gaps in the necessary content to increase worker safety and reduce the violence ${ }^{[19]}$, and tend to be generic online program or video-based content with minimal ED relevance.

A hybrid approach coupling online learning and a tabletop exercise is an effective method to foster successful learning outcomes while addressing the educational gap of workplace violence content ${ }^{[20]}$. The experiences of learners participating in hybrid approaches need to be evaluated so that their feedback can be used to support and improve the educational experience. Our study is significant to nursing practice, because the educational intervention provided a high quality educational program specifically tailored to ED workers deemed as high risk for victimization; an essential step 
towards creating a safer work environment ${ }^{[12,15]}$. Significance to the scholarship of teaching and learning includes providing violence prevention education using a tabletop exercise that allows learners to practice and interact during simulated situations promoting knowledge acquisition and retention. In addition, our findings will allow us to develop and improve hybrid educational designs that increase the knowledge retention of practicing nurses.

\section{Theoretical framework}

Situated cognition theory, provides an effective framework for examining methodologies to increase knowledge acquisition and retention. The learning theory is based upon the belief that learners need to be placed into a situational context before learning will occur ${ }^{[21]}$. As students engage and practice within an environment where the knowledge is applied, both knowledge acquisition and retention are increased. Knowledge constructed individually is further enhanced by the co-construction and social setting of learning alongside others as the learning experience is interpreted and shared ${ }^{[22]}$. This frame shifts learners' roles from passive to active and facilitates the acquisition of new concepts and procedures. This theory guided the development of the study aim.

\section{Methods}

\subsection{Study design}

A qualitative descriptive design was used. The aim of this study was to describe how the delivery of a hybrid program contributes to learning outcomes.

\subsection{Setting and sample}

Participants were recruited from two large urban EDs in the Midwest United States: one a Level I pediatric trauma center and the other a Level I adult/pediatric trauma center. Together the study sites employed 399 non-physician ED workers (e.g., registered nurses, paramedics, patient care assistants) with 387 workers that completed the training deemed eligible to participate in this study.

\subsection{Procedures}

Employees at both study sites completed a revised version of the hybrid educational program reported on by Gillespie, Gates, and Mentzel ${ }^{[20]}$. Employees began the program by completing three asynchronous online modules during June and July 2011. Module 1 focused on workplace violence prevention (e.g., risk assessment, effective communication, identifying patient needs, environmental safety). Module 2 focused on safely managing incidents of workplace violence (e.g., responding to violent incidents, coordinated team approach). Module 3 focused on the post-incident response (e.g., injury care, incident reporting). The online modules took approximately three hours to complete and could be finished over multiple sessions. After completion of the online modules, employees attended a two-hour classroom-based, interactive tabletop exercise during August/September 2011. During the tabletop exercise, employees watched a series of video vignettes depicting workplace violence from patients and visitors taking place in an adult-based ED. Each vignette was presented as an unfolding case study including an aspect of workplace violence that was structured to foster decision making and discussion. The tabletop exercise provided employees the opportunity to discuss and apply the online learning content, workplace violence policies, and role delineation in collaboration with their ED colleagues.

A convenience sample of employees that completed the hybrid education was recruited to participate in 1 of 4 focus group sessions held on location at the study sites. Each focus group session lasted approximately 60 minutes and was facilitated by the same investigator for consistency. The focus group questions were developed based on the situated cognition theory. The relation of the questions to the theory is provided in Table 1. Focus group sessions were digitally audio-recorded and transcribed verbatim by a professional transcriptionist. Transcripts were audited for accuracy. Data were managed using NVivo-9 (Burlington, MA) qualitative data management software. 
Table 1. Focus group questions.

\begin{tabular}{|c|c|}
\hline Focus Areas & Questions \\
\hline Collective problem solving & How well were you able to problem solve as a group during the tabletop exercise? \\
\hline Displaying multiple roles & $\begin{array}{l}\text { How beneficial was it to have your peers and other disciplines represented for the tabletop exercises? } \\
\text { What is your confidence to manage violent situations as a team following the completion of the } \\
\text { web-based learning modules and the tabletop exercise? }\end{array}$ \\
\hline $\begin{array}{l}\text { Confronting ineffective } \\
\text { strategies and } \\
\text { misconceptions }\end{array}$ & $\begin{array}{l}\text { Tell me about your experience with the web-based learning modules. } \\
\text { Did you learn new content? } \\
\text { Have you been able to apply this content to your clinical practice? } \\
\text { Did the tabletop exercise build upon or reinforce the web-based learning modules? }\end{array}$ \\
\hline $\begin{array}{l}\text { Providing opportunities to } \\
\text { develop collaborative } \\
\text { learning }\end{array}$ & $\begin{array}{l}\text { Tell me about your experience with the tabletop exercise. } \\
\text { What did you like about the tabletop exercise? } \\
\text { Did the tabletop exercise enhance or inhibit your learning experience? } \\
\text { Were the tabletop vignettes realistic? } \\
\text { Were the discussions during the tabletop exercise relevant and meaningful? } \\
\text { What contribution did the tabletop vignettes add to your learning experience? } \\
\text { How was the flow of the case scenario presentations and discussions? }\end{array}$ \\
\hline General questions & $\begin{array}{l}\text { Were there any benefits to completing both the web-based learning modules and the tabletop } \\
\text { exercise? } \\
\text { What would you do to improve the web-based learning modules (e.g., content, delivery)? } \\
\text { What would you do to improve the tabletop exercise? }\end{array}$ \\
\hline
\end{tabular}

\subsection{Analysis}

Transcribed data were analyzed using a constant comparative analysis method described by Lincoln and Guba ${ }^{[23]}$. Data analysis started by coding the first focus group transcript line-by-line to identify important units of information. Each successive focus group was analyzed and compared to previously analyzed and coded transcripts by two authors in order to develop a consistent coding schema. To increase validity of the coding schema, the remaining authors analyzed the coding schema in relation to descriptions and exemplars for each category. An audit trail was generated to maximize the consistency of the data coding. By the end of data analysis, the coding schema represented composite themes and categories of the qualitative data.

\subsection{Ethical considerations}

The study was approved by the university and two hospital Institutional Review Boards. Participation in the study was not a condition of employment. All names spoken during the focus group sessions were replaced by pseudonyms.

\section{Results}

Seventeen participants contributed to the four focus group sessions. All participants were Caucasian. There were 16 females and 1 male. Most participants were registered nurses $(n=14)$ with the remaining participants being paramedics $(n=3)$.

The qualitative analyses of the focus group sessions led to the identification of nine categories. The nine categories fell into three major themes: (1) Implementation of the Intervention, (2) Experience of the Intervention, and (3) Translation of the Intervention. An outline of the resulting themes and categories are displayed in Table 2. 
Table 2. Themes and categories of the research findings.

\begin{tabular}{ll}
\hline Themes & Categories \\
\hline \multirow{3}{*}{ Implementation of the Intervention } & Opportunity for learning \\
& Environment of learning \\
& Uniform training \\
& Conditions of learning \\
Experience of the Intervention & Interdisciplinary learning \\
& Facilitated engagement \\
& Realism \\
& Transferability \\
Translation of the Intervention & Retention \\
\hline
\end{tabular}

\subsection{I mplementation of the intervention}

During the focus group analysis, several topics emerged related to the Implementation of the Intervention. These included references to the opportunity for learning, the learning environment, and the uniformity of the training provided to the healthcare team.

\section{Opportunity for learning}

"Opportunity for Learning" focused on the flexibility of scheduling instruction and participants' ability to complete the education at a time that was convenient for them. Discussions centered on the preference to complete the online training during work hours. One participant said that her coworkers had “... gone to management and were actually taken off the unit so they could go. ..” and complete their education. However, participants also reported difficulties completing online training during work hours and the scheduling of the tabletop exercise sessions. A representative comment is “... I probably got up tons and tons of times during online training so what I got from that probably, I mean, not a whole lot from that just because I can't sit there and consecutively do it.” Another participant said that attending the tabletop exercise session "was made mandatory and you had to come drive here for the class and we were told that we had to do it on our own time. You couldn’t do it when you were scheduled.”

\section{Environment of learning}

"Environment of Learning" included both the physical environment and circumstances associated with the learning experience. Examples consisted of technical difficulties, room design, time required to complete training, and class size. Some learners experienced technical difficulties with the online modules and one group experienced problems with video transmission during the tabletop exercise. Technical difficulties were a source of frustration for more than one learner: “... there was also some technical issues with it, so that was frustrating." Previous experience with online delivery may have been a factor, because one participant said, “. . . I actually like it. I like the web-based, I didn’t have too many problems with it and I'm used to learning web-based, too. So for me it wasn't too difficult.” Participants preferred a traditional auditorium style seating. One participant said of the U-shaped seating arrangement, "It's also like not the most conducive because ... you [the teacher] were sorta standing in the middle and once you got down on the floor [to demonstrate a physical hold], everybody was kinda having to lean over." Multiple participants commented that the online education was "way too long” and one participant said, "It was the longest web-based program I had ever done." Environmentally, the use of small class sizes was viewed as positive for learning and overcrowding a problem, because smaller class sizes “. . . invoke, um, more participation.”

\section{Uniform training}

The implementation of the tabletop exercise was interprofessional. Comments by participants focused on the inclusion or exclusion of certain professional groups. The sub-theme was identified as "Uniform Training”. The importance of having the same education for managing violence known by employees from all professional groups was reported as: "I think it 
helps, because you know kinda what everybody's educational background is and maybe what the steps are gonna be, how they're gonna handle it because we've all taken the same education.” Participants also recommended that other professional groups including security and ED receptionists participate with them in the training.

\subsection{Experience of the intervention}

The second major area from which themes emerged was the Experience of the Intervention itself. Participants described their feelings and responses during the educational intervention.

\section{Conditions of learning}

The first category in this theme consisted of comments on instructional design. Identified as "Conditions of Learning" the substantive comments focused on the methodology by which the content was delivered and how it addressed individual learning style preferences. Participants preferred traditional delivery versus online delivery, scaffolding of content, shorter educational programs, and content relevant to their practice. Many of the comments were directed towards how the content delivery method meshed with their preferences. As an exemplar, “. . . some people probably benefitted more from the e-learning. Not me, I benefitted more from the hands-on and like actually seeing. So you probably covered more of the learning styles that way." Another exemplar was, "It was also nice to have our management there to be able to talk about you know our particular department and particular policies and changes that they're trying to make.”

\section{I nterdisciplinary learning}

Incorporating multiple professional perspectives as parts of the discussion during the tabletop exercise helped learners become aware of the roles of others professions. This category focused on persons in the classroom and the importance of each profession's contribution to the discussion. One participant said, “... We come from it with our own role and our own agenda when we have interactions with patients, but so does every other care member in that team. So it, it was kinda good to see kinda the different perspectives that people sorta brought and I mean they all generally had the same approach to the situation, but ... you know, based on what their role was, it might have varied just a little bit.” A paramedic also addressed the need for interdisciplinary learning by stating, "I felt like having all the different disciplines there was, uh made the class more productive for the entire emergency room I would say versus just focusing on nursing or just focusing on you know one discipline or what not.”

\section{Facilitated engagement}

Participants discussed the interaction between the students and teachers during the tabletop exercise and how teachers fostered engagement through Socratic questioning, refocusing, and using the video vignettes to facilitate discussion. A representative statement was: "And it was more than just information being spewed at you. You got to interact and engage.” The video vignettes contributed greatly to learner engagement. One of the nursing participants said, "I think everyone focused on [the videos]. I think, you know, no one turned away from it. Even if it's just for curiosity, started out like 'Okay, let's see what's going on.' Then of course at the end of it everybody wanted to talk about it. So I mean, I think the video part of it helped with the discussion and the learning."

\section{Realism}

"Realism" was described as the ability to identify personally with the situation presented in the online and classroom learning experiences; that the situation was realistic based upon the learners' personal experiences and being able to identify with the situation. One participant observed about the tabletop exercise, "I think making it real, like it was real patients, you know. Makes us as adult learners learn more, so it was something we could relate to. It wasn't something that wasn't going to happen, you know, in our department." One participant requested increasing the realism of the video vignettes to be applicable to her pediatric ED: "I was trying to envision like that altercation that occurred with that, that escalating guy and Teresa out there at the at the [triage] desk and um and um I'm trying to picture that as triage or as the waiting area and that being the PCA. Like how would that look if it was really our ED or was the greeter desk? I think maybe just making those videos authentic to our department might be better.” 


\subsection{Translation of the intervention}

Within this theme of Translation of the Intervention are the concepts of transferability and retention. Learners describe how they will use the materials presented in the hybrid course.

\section{Transferability}

Participants described the transfer of knowledge from the hybrid program to a live situation. "Transferability" was identified as the ability to apply the knowledge from the program to another situation. Included were descriptions of sustained changes in individual practice or within the department, because of the educational intervention. Overall transferability is seen as the ability to trial, practice, and adopt the violence prevention content. As a participant stated about content initially learned online and then reinforced during the tabletop class, "I've used some of the um, de-escalation and. . . noticing, watching the anxiety build and then, I've used that." Another participant commented on trialing her personal alarm to determine its effectiveness: "I actually um tested out my locator the other day when I was in a room, because you know after having watched all those videos and how easy it is and not just those videos but just in general about how easy it is to kinda get sorta trapped in these rooms and stuff like that. I never really trusted the system that if I hit a panic button, someone would actually come to my rescue. So I did try it out and Joy was in there in like 30 seconds and I was so grateful cause I was like, 'Do people even monitor these things?’”

\section{Retention}

Remembering and forgetting was a subject brought up repeatedly by participants. The category of "Retention" describes the content delivery that contributes to the achievement of learning outcomes. The participants discussed the ability to remember content from the classroom more than the online learning; however, the participants acknowledged the hybrid approach was even better because the tabletop exercise emphasized content they learned during the online delivery. As evidence, one participant noted that she could, "Retain that information better from the tabletop. I definitely remember more from the tabletop than I do from the computer based.” Another participant said, "What was beneficial was [that] it just helped you retain that information more. You learned in the web-based training and then it's reiterated in the tabletop. And you go, 'Oh, that’s right,' and it makes it, you know, you just remember it better.”

\section{Discussion}

The tabletop exercise was overwhelmingly preferred over the online learning modules due to the interprofessional discussion and realistic video vignettes. Gillespie, Gates, Mentzel, Al-Natour, and Kowalenko also reported the preference of classroom versus online delivery; however, their rationale was due to complications that learners experienced with the online delivery ${ }^{[24]}$. Slavich and Zimbardo discussed that active learning occurs when learners have an opportunity to "... reflect on their understanding and examine or explain their thinking” (p. 575) ${ }^{[7]}$. Means et al. conducted a meta-analysis of 45 studies that compared traditional to distance learning approaches and traditional to hybrid learning approaches ${ }^{[2]}$. The mean effect size for the comparison of traditional to hybrid approaches was significantly greater than the mean effect size for traditional to online only approaches $(0.35$ vs. $0.05, p<0.01)$. This finding relates the importance of both an online component to present initial content and reserving the traditional classroom component for examining content using active learning strategies.

The tabletop exercise in our intervention (hybrid approach) provided extensive opportunities for participants to reflect, examine, and explain their thinking in relation to workplace violence prevention. While the online modules were primarily cognitive in nature, the tabletop exercise was specifically designed to address the cognitive, psychomotor, and affective domains of learning through the use of active learning strategies such as class discussion, analyzing/reacting to videos, and role-playing ${ }^{[7]}$. The attention to all three domains of learning may help explain the preference for the tabletop exercise. It remains important to note that even though the classroom component was preferred, both online and classroom approaches 
are critical to the delivery of course content and successfully increasing knowledge ${ }^{[20]}$. As noted by the focus group participants, the online modules allowed the in class time to be minimized.

In our study, learners discussed the inability to complete the online modules during their regular work shift. The online learning modules were designed as voice over PowerPoint presentations with no direct teacher interaction. While the online delivery allowed learners to reflect on the course content, it is possible that participants muted the audio feature, quickly read the slides, and exhausted minimal time to complete and reflect on the information they were receiving. This may also explain the preference for the tabletop exercise and the desire to have dedicated, scheduled time periods where they could watch the presentations and not be dually responsible for providing direct patient care. From a budgetary perspective, scheduling non-clinical time to complete required training will require foresight when developing the annual training budget.

The reliability of a learning management system (LMS) for the delivery of online course content is essential. Rubin, Fernandes, and Avgerinou discussed that student satisfaction with a LMS had an independent significant effect on student's satisfaction with a course ${ }^{[25]}$. In our study, learners consistently reported the unreliability of the LMS to deliver the online content. Unfortunately, when learners left before completing a module, learners' accounts became "stuck" leading the learners into a perpetual loop of re-watching the same module several times before the module would be marked as complete and the next module unlocking. This technical difficulty required the research team to monitor the LMS on a continual basis and manually reset learners' accounts. Two potential causes of the technical difficulty are (1) an ineffectively designed LMS and (2) an unstable Internet connection between our project's LMS server and the site where learners were completing their online modules (e.g., home, hospital).

The Institute of Medicine articulated that a key component of the future of nursing education needs to facilitate multiple professionals learning aside one another ${ }^{[26]}$. The tabletop exercise based on an interprofessional format facilitated active learning by allowing participants to learn about mutual roles and responsibilities as well as problem-solve collaboratively ${ }^{[8]}$. During the delivery of the tabletop exercises, participants often reported not realizing the limitations or expectations of their interprofessional colleagues. Ultimately, interprofessional education as designed in the tabletop exercise can lead to future professional collaboration and a higher degree of critical thinking than would be actualized with a cohort of single discipline learners ${ }^{[26]}$.

Nearly every participant in our focus groups commented positively on the realism of the video vignettes to their experiences as ED employees. An integral quality of any effective simulation exercise is realism which can enhance the active learning that occurs ${ }^{[27-29]}$. To further enhance a simulated learning experience, teachers can incorporate a discussion or debriefing component as we did in our tabletop exercise. Cheng et al. similarly held debriefing interventions as a strategy to aide learners in completely synthesizing knowledge acquired during simulation exercises ${ }^{[27]}$. Another benefit of realism to active learning is the potential to immediately transfer knowledge to practice ${ }^{[28]}$. In our program, realism was enhanced and ensured by having a practicing emergency nurse develop the video scripts and direct the video recordings. In addition, local stakeholders (i.e., employees of the ED) were present, providing feedback and validation as to the realism and relevance of the videos as they were recorded.

Hybrid courses that maintain the same number of classroom contact hours as a traditional classroom-only course can be time intensive for students and faculty as well as potentially costly to design and maintain ${ }^{[30]}$. Salamonson and Lantz found that students preferring traditional instruction scored significantly higher on their final exam $(p=.021)^{[30]}$. This finding may be related to the study sample being undergraduate nursing students who were able to pick up on subtle verbal and nonverbal nuances from the teachers presenting course content during classroom instruction that may indicate the content that is more likely to appear on the final exam. In our study, learners did not have the same pressures to "pass" an exam or course. The goal of the learners in our program was to "attend" and receive a certificate of completion per their department's requirement. Salamonson and Lantz did discuss another possible explanation that could help explain our 
sample's preference for classroom instruction: the employees may be from a generation that has more difficulty with self-guided learning, an integral quality of active learning with an online approach ${ }^{[30]}$. It will be important for teachers to evaluate and weigh the benefits of active learning and costs of course design and delivery when determining the need for traditional classroom learning versus hybrid learning.

\subsection{Recommendations for practice}

Future improvements to the online learning are warranted to further increase the active learning experience. One potential strategy to meet this need is incorporating learner-initiated assignments that would be reviewed at the start of the tabletop exercise $^{[7]}$. Also, adding a discussion board or blog feature to the LMS site will provide learners an opportunity to interact with each other and the teachers as they learn the course content ${ }^{[7]}$. Adopting an interactive teaching-learning method will require a stable LMS. This can be accomplished by housing the course content on the LMS affiliated with the learners' employers (e.g., hospital-based LMS).

If there is a required need to reduce non-clinical hours due to time or budgetary constraints, it may be possible to schedule smaller blocks of time (e.g., 30 minutes) at the start or end of a regularly scheduled clinical shift for learners to complete the online training. Alternatively, during periods of lower census, charge nurses can reassign patient care to other staff members providing learners uninterrupted blocks of time while already at work to complete online learning modules.

Providing an online learning experience that is active and realistic can be costly in both time and money. Learners in our course reported how much they liked the video vignettes. One way to minimize the financial burden of videos for online education is to film a single patient moving through a healthcare encounter that can be used multiple times (e.g., ED arrival to inpatient stay, inpatient stay to home care visit). The longer video can then be spliced to focus on certain aspects related to the specific learning outcomes for that particular course. For example, in our program, the vignette for the patient interacting with the triage nurse could be used in different modules to focus on verbal communication, nonverbal communication, and identifying environmental safety concerns. This same vignette does not need to be exclusive to a single course. The same vignette could be used to discuss race relations in a diversity course and therapeutic communications in a mental health nursing course.

Stanley and Dougherty called for a shift in the paradigm of nursing education ${ }^{[31]}$. Part of the shift was for designing curricula and courses that reflect the past experiences of learners as well as the realistic world in which learners will practice. A strategy to accomplish this feat of designing courses realistic to learners' clinical practice is through a partnership of academicians, healthcare leaders, and expert clinicians. Ideally, the partnership developing the courses and the intended recipients of the courses (i.e., learners) will be interprofessional and not exclusive to the nursing discipline

${ }^{[26]}$. Through this partnership, educational innovation will be applied as well as content that is immediately relevant to clinical practice. To maintain the realism of the course, it will be important that the course content and learning outcomes be periodically reviewed (e.g., every 1-2 years).

\subsection{Limitations}

Findings from this study are limited by a small sample size, lack of generalizability, and limited variability in the occupational roles of participants. Participants in our study were particularly homogenous for sex, race, and profession (i.e., registered nurses and paramedics). It is possible that the learning experience with our hybrid educational program will be different for other ED workers: patient care assistants, respiratory therapists, registration/clerical personnel, security officers, and physicians. In addition, we did not measure age or years of ED experience with our sample. As a result, our findings should be used with caution when making inferences about generational differences for learning preferences. Given the qualitative nature of our study, the findings are not generalizable. In order to increase the transferability of our findings, we did provide a rich description of the narrative data to allow readers to judge for themselves the relevance of our findings to their respective educational/practice settings. 


\section{Conclusion}

An active learning classroom component (i.e., tabletop exercise) was perceived to yield greater knowledge and retention of the workplace violence content compared to the online learning modules for the participants in this study. Consideration of the learning styles and needs of learners should be taken into consideration when developing content for the online delivery or hybrid approach for educational programs. In addition, active learning strategies should be incorporated into online learning and all course content pilot-tested with learners prior to course launch. We recommend that future research be conducted using a participatory action research process for the design, implementation, and evaluation of course content to determine if a fully collaborative process will yield high learning outcomes simultaneously with high course satisfaction on behalf of learners.

\section{References}

[1] Iwasiw CL, Goldenberg D, Andrusyszyn, M-A. Curriculum design. In Curriculum Development in Nursing Education (2nd ed.). Sudbury, MA: Jones and Bartlett. 2009: 195-230.

[2] Means B, Yoyama Y, Murphy R, Bakia M, Jones K. Evaluation of Evidence-Based Practices in Online Learning: A Meta-Analysis and Review of Online Learning Studies. Washington, DC: U.S. Department of Education, 2010.

[3] Macario E, Benton LD, Yuen J, Torres M, Macias-Reynolds V, Holsclaw P, et al. Preparing public health nurses for pandemic influenza through distance learning. Pub Health Nurs. 2007; 24(1): 66-72. PMid:17214655 http://dx.doi.org/10.1111/j.1525-1446.2006.00609.x

[4] Clark RC, Mayer RE. e-Learning and the Science of Instruction: Proven Guidelines for Consumers and Designers of Multimedia Learning (2nd ed.). San Francisco, CA: Wiley \& Sons, 2008.

[5] Ebert-May D, Brewer C. Innovative in large lectures-teaching for active learning. Bioscience. 1997; 47(9): 601-607. http://dx.doi.org/10.2307/1313166

[6] Bonwell C, Eison J. Active Learning: Creating Excitement in the Classroom. AEHE-ERIC Higher Education Report, No. 1. Washington, D.C.: Jossey-Bass, 1991.

[7] Slavich GM, Zimbardo PG. Transformational teaching: Theoretical underpinnings, basic principles, and core methods. Educ Psych Rev. 2012; 24: 569-608. http://dx.doi.org/10.1007/s10648-012-9199-6

[8] Emergency Management Institute. The tabletop exercise. In Exercise Design. Emmitsburg, MD: Federal Emergency Management Agency. 2010; 5.1-5.25.

[9] Dausey DJ, Buehler JW, Lurie N. Designing and conducting tabletop exercises to assess public health preparedness for manmade and naturally occurring biological threats. BMC Pub Health. 2007; 7: 92-99. http://dx.doi.org/10.1186/1471-2458-7-92

[10] Federal Emergency Management Agency. NIMS compliance metrics: Terms of reference, 2007. Available from: http://www.fema.gov/pdf/emergency/nims/comp_met_terms.pdf

[11] Gacki-Smith J, Juarez AM, Boyett L, Homeyer C, Robinson L, MacLean SL. Violence against nurses working in us emergency departments. J Nurs Admin. 2009; 39(7/8): 340-349. PMid:19641432 http://dx.doi.org/10.1097/NNA.0b013e3181ae97db

[12] Gates DM, Gillespie GL, Kowalenko T, Succop P, Sanker M, Farra S. Occupational and demographic factors associated with violence in the emergency department. Adv Emerg Nurs J. 2011; 33(4): 303-313. http://dx.doi.org/10.1097/TME.0b013e3182330530

[13] Gates DM, Gillespie GL, Succop P. Violence against nurses and its impact on stress and productivity. J Nurs Econ. 2011; 29(2): 59-66.

[14] Gillespie GL, Gates DM, Berry P. Stressful incidents of physical violence against emergency nurses. OJIN: The Online J Issues Nurs. 2013; 18(1): manuscript 2. http://dx.doi.org/10.3912/OJIN.Vol18No01Man02

[15] Gillespie GL, Gates DM, Miller M, Howard PK. Violence against healthcare workers in a pediatric emergency department. Adv Emerg Nurs J. 2010; 32(1): 68-82. http://dx.doi.org/10.1097/TME.0b013e3181c8b0b4

[16] Kowalenko T, Gates DM, Gillespie GL, Succop P, Mentzel T. Prospective study of violence against ED workers. Am J Emerg Med. 2013; 31(1): 197-205. http://dx.doi.org/10.1016/j.ajem.2012.07.010

[17] The Joint Commission. Preventing Violence in the Health Care Setting. Sentinel Event Alert 45, 2010. Available from: http://www.jointcommission.org/sentinelevents/sentineleventalert/sea_45.htm

[18] Gates DM, Ross CS, McQueen L. Violence against emergency department workers. J Emerg Med. 2006 ; 31 : $331-337$. PMid:16982376 http://dx.doi.org/10.1016/j.jemermed.2005.12.028 
[19] Peek-Asa C, Casteel C, Allareddy V, Nocera M, Goldmacher S, O’Hagan E, et al. Workplace violence prevention programs in hospital emergency departments. J Occup Env Med. 2007; 49(7): 757-763. http://dx.doi.org/10.1097/JOM.0b013e318076b7eb

[20] Gillespie GL, Gates DM, Mentzel T. An educational program to prevent, manage, and recover from workplace violence. Adv Emerg Nurs J. 2012; 34(4): 325-332. http://dx.doi.org/10.1097/TME.0b013e318267b8a9

[21] Brown JS, Collins A, Duguid P. Situated cognition and the culture of learning. Educ Res. 1989; 18(1): 32-41.

[22] Lave J, Wenger E. Situated learning: Legitimate peripheral participation. Learning in doing: Social, cognitive and computational perspectives. New York City, NY: Cambridge University Press, 2003.

[23] Lincoln YS, Guba EG. Naturalistic Inquiry. Newbury Park, CA: SAGE, 1985

[24] Gillespie GL, Gates DM, Mentzel T, Al-Natour A, Kowalenko T. Evaluation of a comprehensive ED violence prevention program. J Emerg Nurs. 2013; in press. http://dx.doi.org/10.1016/j.jen.2012.12.010

[25] Rubin B, Fernandes R, Avgerinou MD. The effects of technology on the Community of Inquiry and satisfaction with online courses. Internet Higher Educ. 2013; 17: 48-57. http://dx.doi.org/10.1016/j.iheduc.2012.09.006

[26] Institute of Medicine. Transforming education. The Future of Nursing: Leading Change, Advancing Health. Washington, DC: The National Academies Press. 2011: 163-219.

[27] Cheng A, Rodgers DL, van der Jagt E, Eppich W, O’Donnell J. Evolution of the Pediatric Advanced Life Support course: Enhanced learning with a new debriefing tool and web-based module for Pediatric Advanced Life Support instructors. Ped Crit Care Med. 2012; 13(5): 589-595. PMid:22596070 http://dx.doi.org/10.1097/PCC.0b013e3182417709

[28] Davies J, Nathan M, Clarke D. An evaluation of a complex simulated scenario with final year undergraduate children's nursing students. Collegian. 2012; 19: 131-138. http://dx.doi.org/10.1016/j.colegn.2012.04.005

[29] Kable AK, Arthur C, Levett-Jones T, Reid-Searl K. Student evaluation of simulation in undergraduate nursing programs in Australia using quality indicators. Nurs Health Sciences. 2012, in press. http://dx.doi.org/10.1111/nhs.12025

[30] Salamonson Y, Lantz J. Factors influencing nursing students’ preference for a hybrid format delivery in a pathophysiology course. Nurs Educ Today. 2005; 25: 9-16. PMid:15607242 http://dx.doi.org/10.1016/j.nedt.2004.09.006

[31] Stanley MJC, Dougherty JP. A paradigm shift in nursing education: A new model. Nurs Educ Perspectives. 2010; 31(6): 378-380. PMid:21280445 